\title{
Income and Trustworthiness
}

\author{
John Ermisch, ${ }^{a}$ Diego Gambettab
}

a) University of Oxford; b) European University Institute

Abstract: We employ a behavioral measure of trustworthiness obtained from a trust game carried out with a sample of the general British population, the individuals of which were extensively interviewed on earlier occasions. Our basic finding is that given past income, higher current income increases trustworthiness and, given current income, higher past income reduces trustworthiness. Past income determines the level of financial aspirations, and whether or not these aspirations are fulfilled by the level of current income affects trustworthiness.

Keywords: trustworthiness; absolute income; relative income

Citation: Ermisch, John, and Diego Gambetta. 2016. "Income and Trustworthiness." Sociological Science 3: 710-729.

Received: March 9, 2016

Accepted: April 13, 2016

Published: August 17, 2016

Editor(s): Jesper Sørensen, Delia Baldassarri

DOI: $10.15195 / \mathrm{v3} . \mathrm{a} 30$

Copyright: (C) 2016 The Author(s). This open-access article has been published under a Creative Commons Attribution License, which allows unrestricted use, distribution and reproduction, in any form, as long as the original author and source have been credited. (C) (i)
$\mathbf{T}^{\mathrm{N}}$ the last quarter century, the scholarly literature on trust has reached gigan1 tic proportions, ${ }^{1}$ but it suffers from a serious imbalance: of the two choice components of trust, deciding whether to trust and deciding whether to be trustworthy, it is the former that gets the lion's share of attention while the latter remains under-investigated. We still know relatively little about trustworthiness and the mechanisms that govern it. Here we use a behavioral measure of trustworthiness, obtained from a "trust game" played by people from a previously surveyed sample of the general British population, to address a fundamental question, namely whether income affects trustworthiness: does higher income, whether in absolute or relative terms, make people more or less trustworthy?

A common feature of trust-related decisions is that trustworthiness is a pro-social behavior that comes at some personal cost. There are many forces that can tame self-interest and sustain trustworthiness. Some are generally applicable personal dispositions, such as fairness, honesty, and reciprocity, and others apply in particular trust situations. Regardless of which force is at work, it is plausible to conjecture that at the margin, the perception of the cost of trustworthiness and the resources to bear it would be related to a person's income. This is most evident in financial interactions, such as the one in the trust game we use in our study. The question of how and how much people's income matters in determining their trustworthiness is not just interesting in itself, but has implications for the consequences of business cycles, economic growth, and income distribution.

The imbalance between the attention paid to trust and to trustworthiness is partly due to problems of measurement. Surveys are not a good tool since attitudinal questions about a person's trustworthiness would not, for obvious reasons, engender credible answers. ${ }^{2}$ An alternative approach is to measure trust and trustworthiness through experiments that use real monetary rewards. This method has the advantage of providing a behavioral measure of trustworthiness. In addition, three important elements of trust decisions can easily be made clear in experiments: the stakes, the type of situation in which trust is an issue (usually a simple financial transaction), and the reference group that subjects have in mind when making their 
decisions (usually other anonymous subjects in the same experiment). Unlike surveys however, experiments are often administered to students, usually self-selected subjects, who are unrepresentative of the adult population and who possess important knowledge about the "strangers" with whom they are interacting-other students. In addition, they typically lack information on individual attributes needed to investigate the individual-level correlates of trustworthiness.

In this article, we overcome both sets of limitations by exploiting an innovative design seldom used before (Fehr et al. 2002) that combines the experimental method with the survey method: first, to elicit a behavioral measure of trustworthiness, we use a version of the so-called "trust game" described in detail in Ermisch et al. (2009). This version differs from the trust game used in most trust experiments in ways that we believe allow it to provide better measures of the concepts of trust and trustworthiness. Next, we employ a sample of the general U.K. population, the individuals of which were extensively interviewed on earlier occasions and many of whose attributes are thus known. ${ }^{3}$ The data we obtain, linking the trust game with the panel survey, are to our knowledge the richest available to address our question.

Our main contributions are to provide a behavioral measure of trustworthiness in a survey context and to understand better how trustworthiness between strangers varies within the population in relation to individuals' income. We do not manipulate our main "treatment variables" experimentally, but rather relate variation in trustworthiness outcomes in the trust game to variation in attributes within the population, focusing on the effects of income on trustworthiness. Our main finding is that higher current income relative to past income increases a person's propensity to be trustworthy in interactions with strangers. The proposed mechanisms as to why such an increase in "relative income" increases trustworthiness suggest this may be a causal effect, but, as it is identified by income variation among people, we cannot rule out the possibility that the association reflects heterogeneity (i.e., people with higher current relative to past income are also more trustworthy).

The article proceeds as follows. First, we summarize the little we know about the relation between income and trustworthiness. Next, we clarify what we mean by "trust" and "trustworthiness" and what might influence the latter, focusing in particular on people's economic resources. We then explain the trust game we use and its key features. Next, we describe the sampling frame and survey methods. Fourth, we present the main outcomes of the trust game, and the following three sections examine the main questions of the paper: how do economic resources affect trustworthiness in trust situations involving strangers. The final section presents our conclusions.

\section{Income and Trustworthiness: What We Know}

Most research that measures trustworthiness-most often through a trust game of the kind we use here and describe below-does not have data on income, and that which does rarely focuses on this question. Moreover, the limited evidence we have is inconclusive: Bellemare and Kröger (2007) and Fehr et al. (2002), adopting a design similar to the one we adopt, find no effects for current income, whether 
on trust or trustworthiness. Barr and Serneels (2006), in a sample of 164 workers from a number of Ghanaian firms, find instead a positive correlation between second mover's earnings and the odds of returning more than the amount sent by the first mover (both players are in the same firm and they know it). Bonein and Serra (2009:784), in a sample of 148 undergraduates, find that a measure of disposable income (which they do not describe) is negatively correlated with the odds of returning something in a standard trust game experiment. Becchetti and Conzo (2009, Table 7) also find a negative correlation: they use the sum of each family member's disposable income as measure, the data on trustworthiness from a trust game experiment with 152 microfinance borrowers in Argentina, and a control group of non-borrowers of the same size (although household income is only one of two determinants of trustees' decisions to be significant in the regression, they do not discuss the finding). Finally, in the only research to address the effect of relative income, Kropp et al. (2009:67) find that "while the absolute level of family income had no significant effect on repayment behavior, U.S. borrowers that perceive themselves as having a family income that was relatively lower than other U.S. households repaid at higher rate."

\section{Trust}

We work with a notion of trust that relates trust to specific acts and makes it easy to capture it empirically (Bacharach and Gambetta 2001). We trust when we trust that someone will do $\mathrm{X}$ - e.g., repay a loan, pay the fare, perform a given task as expected, etc. The trust that we have in someone doing $X$ does not necessarily extend to trust in that same person doing Y. We say that a person "trusts someone to do $X "$ if she (the truster) acts on the expectation that he (the trustee) will do $X$ when both truster and trustee know that two conditions obtain:

1. If he fails to do X, she would have done better to act otherwise--"If I knew he was a cheat, I would not have lent him the money." If trust is fulfilled, the truster is better off than had she not trusted, but if trust is not fulfilled, she is worse off.

2. The truster acting in the way she does gives him the opportunity to pursue a selfish reason not to do X-"If I hadn't lent him the money, he could not have cheated me."

A trustworthy trustee is simply one who does $X$ when those two conditions obtain.

\section{Trustworthiness}

In all experiments aimed at measuring trust and trustworthiness, these notions are not addressed in general-an impossible task—but refer to a financial "game" in which players can earn real money: the trustee's monetary payoffs are such that a rational, self-interested trustee should never fulfil trust and, expecting that, 
the rational, self-interested truster should never trust. Because, however, there is overwhelming evidence in real life as well as in experiments that a considerable number of players trust and fulfil trust, there must be something that makes some trustees trustworthy, namely, capable of resisting the pull of their self-interested or raw payoffs and prefer to be trustworthy even in one-shot games (the framework we use to understand trustworthiness derives from Bacharach and Gambetta 2001).

The primary trust dilemma of the truster thus consists in deciding whether the trustee will be motivated by raw monetary payoffs or whether what we may call his all-in payoffs differ and make him trustworthy. In other words, to have a problem of trust at all requires that the truster can at least conceive that a trustee could be motivated by self-interest and thus be untrustworthy whenever it pays off; but, for the truster to even think of trusting, he has to conceive of the possibility that the trustee could be motivated by forces capable of overriding his raw payoffs and, when all things are considered by the trustee, yield payoffs compatible with being trustworthy.

What are these forces, these trust-warranting properties (TWPs) that can tame self-interest? There is a plethora of candidates. There are "global" TWPs that sustain trustworthiness in a wide range of encounters: these include fairness, honesty, reciprocity, and trust-responsiveness, the sense of obligation to fulfil the trust that is put in one. ${ }^{4}$ Even people who are neither fair-minded nor reciprocal can still have reasons to be trustworthy and stick to their promises. They may fear postmortem divine retribution or be socialized to respect contracts and act in a manner to promote good will in others. Furthermore, trustworthiness can be an eminently "local" response that depends on what one is being trusted about. Someone may be solidly trustworthy as a father and yet an opportunist with his colleagues or the Inland Revenue. Love of children may be a TWP that sustains trustworthiness only in relationships that involve children's welfare.

Three conclusions can be drawn from the above. First, the design of a trust game to measure trustworthiness should try to elicit as wide a range of TWPs as that which can make a trustee trustworthy in that situation in real life.

Next, because in any one trust situation more than one property can be motivating the trustworthy action and a different set of properties can be active in different situations, seeking an overarching theory of trustworthiness, even if only in financial transactions, is not a feasible or even meaningful aim.

Lastly, TWPs share one feature: they are not directly observable. What we (and trusters) can observe (when they can observe anything at all) are the individual attributes and behaviors that may activate or hinder trust-warranting properties. In this article, we focus on the TWPs that could be associated with trustees' income, both absolute and relative.

\section{Hypotheses}

One could think, first of all, that what matters is the absolute level of income. This it could do in two opposite directions. The simplest idea would be that people who have more resources feel more disposed to be trustworthy in a financial exchangethe same cost of being trustworthy weighs proportionally less on their finances 
than it does on those of poorer people. For instance, taxi drivers make such an assumption when they display a preference for picking up richer customers whom they deem unlikely to do a "runner" on them to avoid paying the taxi fare (Gambetta and Hamill 2005). This would represent a causal effect of income. Alternatively, through a "selection effect," one could expect a negative association between income and trustworthiness to dominate: richer people are richer because they pursue their self-interest more vigorously, with less regard for others, whereas poorer people are poorer because they are more inclined to share and take a collective approach to welfare rather than an individualistic one.

Instead of absolute levels of income, however, a subtler expectation would be that it is relative income that matters. It is not whether one is rich or poor, but whether one feels richer or poorer that makes the difference. In this article, we investigate relative income with reference to the subject's past income and not with reference to the income of others (as in Kropp et al. 2009), which our design does not allow us to measure.

According to the psychological theory of adaptation (or "habituation"), people get used to a stimulus as it persists over time, but are responsive to changes in circumstances, including financial ones. ${ }^{5}$ The effect of changes in income could in turn be interpreted as having two effects on trustworthiness. One is related to the notion of reference points in "prospect theory" (Kahneman and Tversky 1979); for instance, those who have recently experienced an improvement in their financial situation are above their reference point, and they perceive being trustworthy as cheaper. ${ }^{6}$ Alternatively, they may feel richer as a result of the improvement, and this may cause them to act more benevolently and generously towards others. In the former case, the driving mechanism would be a cost calculation biased downwardly by the experience of a financial improvement; in the latter, it would be a positive emotional state induced by the improvement. But, in practice, it is difficult to distinguish between the two because perceived lower costs make you feel better off as well.

\section{The Game}

The game presented to subjects, whom we shall call the truster $(\mathrm{R}, \mathrm{a}$ "she" for convenience) and the trustee (E, a "he"), is a basic "one-shot" trust game in binary form. $R$ receives a $£ 10$ banknote at the onset of a professional interviewer's visit to her home; it is described as compensation for taking part in the interview cum game. $R$ is told that she will have the opportunity to obtain $£ 22$ if she gives the $£ 10$ banknote to another person (E) with whom she has been randomly matched and about whom she is told nothing. She is told that the administrator will increase it by $£ 30$, and so $E$ will receive $£ 40$ total; $E$ will then be given the choice to either pay back $£ 22$ to $R$ or keep all $£ 40$. $R$ is informed that if she decides to give $£ 10$, she will know the outcome in about four weeks, and if E decides to pay back the specified amount, she will receive a check for $£ 22$. The procedures ensure that the interviewer does not observe or otherwise know her decision (for further details see Ermisch et al. 2009). The basic structure of the game is illustrated in Figure 1. 


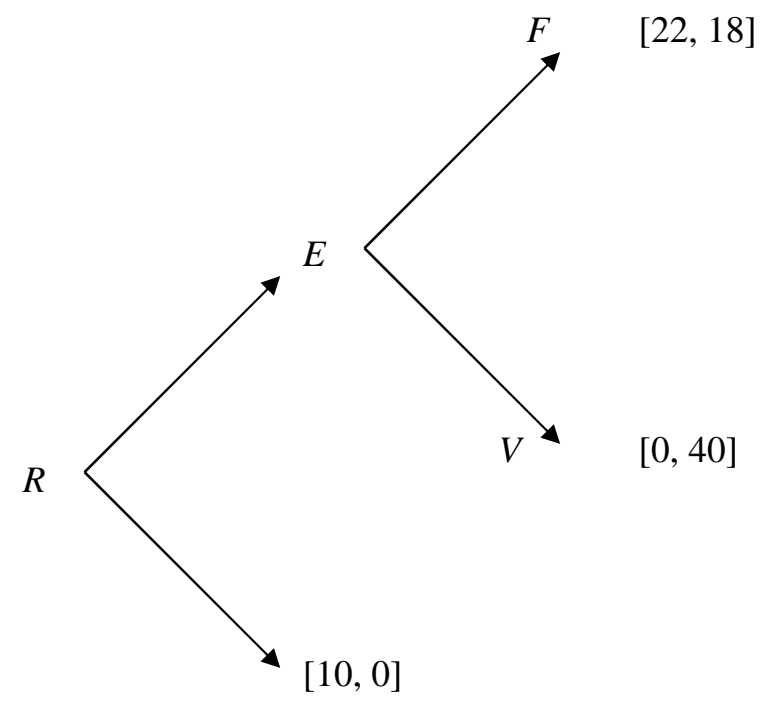

( $\mathrm{F}$ = "fulfill trust," V = "violate trust"; R's payoffs listed first in brackets)

Figure 1: Structure of the trust game and payoffs.

If $R$ keeps the $£ 10$, the game simply ends there. If $R$ chooses to pass the $£ 10$ on, $E$ enters the picture, and he is the focus of the analysis in this paper. $\mathrm{E}$ is offered, by a different interviewer who visits him at his home, a binary choice of whether to pay back $£ 22$ and keep the difference or keep the whole $£ 40$ he received. $E$ is told that $\mathrm{R}$ was informed that $\mathrm{E}$ would be making this choice before $\mathrm{R}$ decided to pass on $£ 10$. $E$ is given two checks made out in his name: one for $£ 40$ and one for $£ 18$, either of which he can cash without delay (the other is placed in the decision envelope and sealed). Again, the interviewer does not know his decision. The procedures are thus, in a sense, "double blind": the interviewer knows the subjects' names and addresses, but not their decisions, whereas the researcher knows the subjects' decisions, but identifies them by their code numbers, not associating them to their names or addresses.

The amount specified to be paid back in the case that $\mathrm{E}$ fulfils trust was chosen to make the payoffs asymmetric. Symmetric payments may encourage fulfilling trust for reasons of fairness rather than because $\mathrm{E}$ does what is expected of him (e.g., see Bacharach and Gambetta 2001; Bohnet and Huck 2004; and Bohnet et al. 2005). 
For one half of the sample, we used a second "payoff treatment" in which $\mathrm{R}$ receives $£ 12$ in cash (a $£ 10$ note and a $£ 2$ coin) as compensation for taking part in the interview cum experiment. $\mathrm{R}$ is offered the binary choice of either keeping the whole $£ 12$ or giving $£ 10$ to $E$ and keeping $£ 2$. The remaining steps are the same as in the previous treatment. The outcome variable of interest is the probability that $\mathrm{E}$ pays back the $£ 22$ ("fulfils trust").

\section{Key Features of Our Design}

Our design differs from that of the standard trust game (TG) (Berg, Dickhaut, and McCabe 1995; Glaeser et al. 2000) also used by Fehr et al. (2002) and Bellemare and Kröger (2007) in which R could pass on any fraction of the $£ 10$, and E could return any fraction of double or triple the initial amount passed on by $\mathrm{R}$. In addition, the standard TG is designed in such a way as to tap only into reciprocity or fairness as the TWPs that can lead E to return enough money to R, which, although important, are not the only ones (not even perhaps the main ones). Ermisch and Gambetta (2006) provide a detailed critique of this design, arguing that it lacks the basic features of a trust situation even in a one-shot case, and, as a result, it blurs the link with clear notions of trust and trustworthiness and introduces confounding effects.

Our design, by contrast, precisely captures clear notions of trust and trustworthiness. This is because $\mathrm{R}$ knows in advance how much she can expect back from $\mathrm{E}$ if $\mathrm{E}$ fulfils trust, and $\mathrm{E}$ knows that this is an expectation of $\mathrm{R}$ when she makes her decision. E thus knows that he cannot be just a little more or a little less trustworthy; he has to choose whether to be trustworthy or not. Thus, in our binary TG, it is clear what trusting and trustworthiness are, as is common in real life (e.g., making and repaying a loan). We further believe that our design strongly encourages $E$ to put himself in the situation of a person who has benefited from R's expectation that he will return $£ 22$.

Insofar as beliefs are based on experience, past experience is important for people's decisions in experiments. It is precisely participants drawing on their social context that should give our game external validity. We believe that our design makes it highly likely that trustees' decisions reflect their habitual practices in these situations - their sense of reciprocity, fairness, or sensitivity to obligationsand that the decisions of trusters reflect their expectations of such behavior. In addition, the study by Karlan (2005) of poor Peruvian women participating in a micro-credit program indicated that Es in the standard TG who returned a larger proportion are less likely to default on their loan from the program, suggesting that the trust game behavior indeed reflects individual-specific trustworthiness.

As noted above, we introduce two payoff structures. We expect that the treatment in which $\mathrm{R}$ has the draconian option of parting with all her money or keeping it all will increase the chances that $\mathrm{E}$ will pay his due back if $\mathrm{R}$ passes the money on. The reason we expect $\mathrm{E}$ to be less inclined to return the money in the non-draconian case is that we think that leaving $R$ with a payoff of $£ 2$ will give $E$ a way out, by making him feel less guilty about not fulfilling trust: $E$ will feel that $R$ does not suffer a total loss of face and that he is not leaving her with a worrisome and salient nothing. 


\section{The Sample and Survey Methods}

The sample frame was households that were formerly members of the British Household Panel Survey (BHPS); they were an over-sample of poorer people recruited in 1997, dropped from the panel for technical and funding reasons in 2001, and reinterviewed in 2003 for a special study (Jäckle et al 2004). In 2007, we randomly selected one person from each household. An advance letter asking these persons whether they would agree to participate explained that we would be "running an experiment on how people make simple financial decisions" as well as asking questions from a short questionnaire similar to earlier ones. An advantage of using a sample drawn from people who have participated in the BHPS for a number of years is that they are likely to believe that the field organization and the managers of the survey can be trusted to carry out the game and payments in the way that they promise. Trust responses in a new survey are likely to be contaminated by varying degrees of trust in the organizers of the experiment in addition to trust in their co-player. Also, these subjects are used to receiving compensation (a voucher) for their participation. The game and subsequent interviews were carried out face-to-face by professional interviewers at the subject's home. Interviewers were instructed to read only from the game's script and not to elaborate further. The sample targets for Rs and Es were based on the expectation (based on previous research) that about 40 percent of Rs would pass on the money. We randomly matched E-players to the Rs who passed on the money. It turned out that there were 12 Es who were unmatched because we exhausted the sampling frame for Rs. As a consequence, we were not able to interview as many Rs as we wanted. As these 12 Es thought they were responding to Rs (and in good faith we thought they were too), it is still valuable to analyze their decisions.

The game was carried out first. The two payoff treatments were applied to one half of the sampled Rs each. After completing the experiment, the respondents completed a short questionnaire with the interviewer and another confidential self-completion questionnaire. On average, the game took 10 minutes and the remainder of the survey about 15 minutes.

Almost all of the non-response to the game/survey arose because of inability to locate the selected individual who had moved house. Because we know that the probability of moving in a particular year is inversely related to length of current residence (e.g., Morrison [1971] for an early study and Belot and Ermisch [2009] for evidence from the BHPS), we checked whether non-response may have affected our inferences by relating the odds of giving the $£ 10$ (among Rs) and returning the $£ 22$ (among Es) to length of residence. We found no significant effects even after controlling for other variables that may affect trust or trustworthiness. Thus, it appears that those who move more often do not behave differently in terms of trust and trustworthiness.

Because of its origin, our sample differs from the British population in a number of potentially important dimensions: it over-represents women, people who are retired, older, divorced, or separated, and those with lower incomes. At a minimum, our sample can be taken as representative of households with low to moderate income. The focus on lower-income people may have its serendipitous advantages 
for estimating the relationship between trustworthiness and income because the sums of money involved in the experiment, particularly the $£ 40$ that Es receive, may be more important to them. But it also means that the mean proportion observed returning $£ 22$ in the game would understate trustworthiness in the population if higher income raises trustworthiness.

\section{Basic Results}

Overall, we find that about two-fifths of people are willing to trust strangers by giving them $£ 10$ in the expectation of receiving $£ 22$ if the stranger is trustworthy. Just over one half of strangers fulfil their trust, resisting the temptation of keeping $£ 40$ rather than only $£ 18$. A larger percentage of Es return $£ 22$ in the all-or-nothing treatment as we expected (Figure 2), although the difference is not statistically significant at conventional levels. Still, we cannot rule out that the thought of $R$ being left with $£ 2$ rather than with no money at all inclines $E$ to be untrustworthy. This could explain the puzzling finding of many trust experiments whereby in many cases, the second mover sends only a little money back, but not enough to cover the sum sent over by the first mover-arguably a guilt-allaying "tip" rather than a clear, trustworthy act. What does motivate one half of these subjects to resist the temptation to pocket $£ 40$ and to instead return $£ 22$ to the trusters? Before investigating the effect of income, we estimated logit regressions that relate being trustworthy (TW) to variables that have sometimes been found to be associated with return behavior in other TG. People with some educational qualifications and the divorced, separated, or widowed are more likely to be TW in the trust game, whereas those in good health tend to be less TW (see Table 1 in the online supplement, which includes means of the variables).

\section{Incomes, Current and Past}

Our two hypotheses are: (1) absolute current income is associated with TW, and (2) higher current income relative to past income ("relative income") increases TW. Our measures are as follows.

For current income, we use a banded household income question that was asked in the survey we carried out following the game. There are ten bands; the lowest is less than $£ 150$ a week and the highest is more than $£ 1,150$ (2007 prices). In all the intermediate bands, we use the mid-point value. For the two extreme bands, we took from the 2007 BHPS the average value of income for people in those bands ( $£ 90$ and $£ 1,615$, respectively). Quartiles, mean, and standard deviation of the distribution of log household income from the study sample are shown in Table 2 in the online supplement along with the corresponding statistics for a representative sample from the 2007 BHPS. The much lower average level of income in the study sample reflects its origins as an over-sample of poorer people.

Our primary measure of relative income is the ratio of current income to a measure of past income in the years 1997-2001. Our study was carried out in 2007, but we lack income information for the interim years; nevertheless, the correlation 


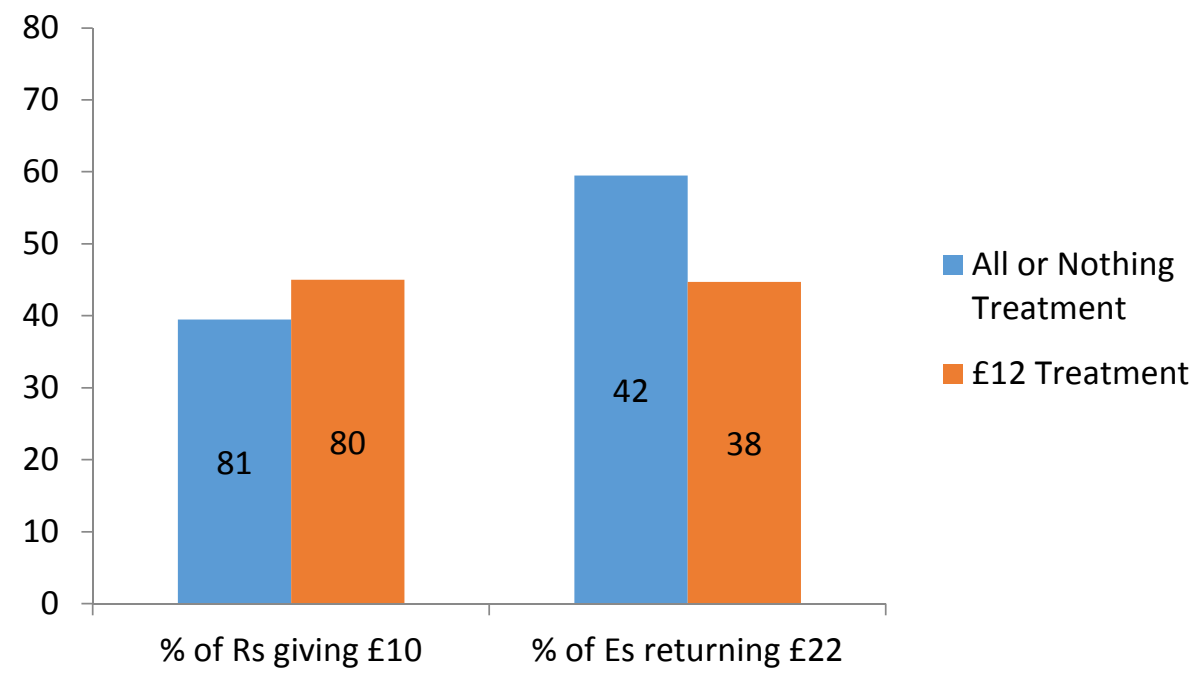

Figure 2: All or nothing treatment effect. (Ns in the columns).

between average log household income during 2002-2006 and that for 1997-2001 among participants in the 2007 BHPS was 0.74 . We obtain the past income measure by exploiting the sampling frame described earlier, which provides five years of panel information for the individuals in our sample. In the BHPS, each individual in the household was asked to report income in the past month from a large number of sources (e.g., earnings, benefits, etc.). Not only are these reports elicited by detailed questions but each individual's own income is also aggregated into household income in a consistent manner. We take the average of log household income during this five-year period, which should remove much of the transitory fluctuations in past income and reduce measurement error, particularly desirable given our small sample. Table 2 in the online supplement shows that, compared to $2007 \log$ income in the study sample, the distribution of average log past income is more compressed, as we would expect; its standard deviation is 0.54 compared to 0.86 for current income. We work with the logarithm of relative income. In our study sample of poorer people, its mean is negative, but positive for BHPS respondents, indicating that the study sample is more likely to experience declines in income between the period 1997-2001 and 2007 than the BHPS respondents. The correlation coefficient between current and past average log income is $0.54 .^{7}$ 


\section{Absolute Income Effects}

On the one hand, people who have more resources may feel more disposed to be trustworthy in a financial exchange; on the other hand, richer people may be a select group who are richer because they pursue their self-interest with less regard for others, leading to a negative association between absolute income and TW-not an "effect" of income per se. The latter idea has a parallel in the work by Piff et al. (2010, 2012), who find evidence consistent with the hypothesis that "lower class" people are more concerned with the needs of others than "upper class" people and so will act in a more pro-social manner to improve others' welfare. ${ }^{8}$ Piff et al (2012:4086) provide evidence that "upper-class individuals' selfish tendencies are accounted for, in part, by their more favourable attitudes toward greed."

The first column of Table 1 introduces the logarithm of current absolute income measure, and its positive coefficient provides support for the former interpretation: more resources increase TW (because one half of our sample is trustworthy, the logit coefficients can be transformed to approximate effects on the probability of TW around the average by multiplying by 0.25$).{ }^{9}$ Consistent with this interpretation is that persons with qualifications are more likely to be TW (Table 3 in the online supplement). The effects of age and gender are virtually zero, and so we drop them in subsequent specifications with the income measures (the p-value of the test of their exclusion is 0.97 ); the second column of Table 1 shows little change in the current income coefficient when we do so. When measures of a person's own or their father's social class are introduced into the model, their coefficients have large standard errors and the estimated impact of income changes little (results not shown).

As we have a household income measure, it would be preferable to control for household size, but because the study sample was individual-based, information about other household members was not collected. To address this, we use the mean size of the household in which the person lived during 1997-2001. Using members of the 2007 BHPS for comparison indicates that the correlation between 2007 household size and mean size during 1997-2001 is 0.67. The third column of Table 1 shows that household size has a negative effect and that controlling for household size increases the positive impact of current household income substantially. The increase suggests that the effect of household size reflects an impact of scarcer resources in a larger household.

The fourth column introduces average log income during 1997-2001, which has a strong negative impact on TW; furthermore, the impact of current log income increases. That is, current income matters, but its impact is underestimated if we do not control for past income. We cannot reject the hypothesis that the magnitudes of the current and past log income coefficients are the same (the p-value of the test is $0.64)$. This finding points to a relative income interpretation, which we consider in the next section. 
Table 1: Logit regression of impacts of current absolute income on trustworthiness.

\begin{tabular}{|c|c|c|c|c|}
\hline Return $£ 22$ & 1 & 2 & 3 & 4 \\
\hline Current household income $(\log )($ mean $=7.05)$ & $\begin{array}{c}0.64^{*} \\
(0.25)\end{array}$ & $\begin{array}{c}0.63^{*} \\
(0.28)\end{array}$ & $\begin{array}{c}1.00^{*} \\
(0.31)\end{array}$ & $\begin{array}{c}1.56^{*} \\
(0.40)\end{array}$ \\
\hline Average log household income, 1997-2001 $($ mean $=7.18)$ & & & & $\begin{array}{r}-1.87^{*} \\
(0.79)\end{array}$ \\
\hline Mean household size, 1997-2001 $($ mean $=2.47)$ & & & $\begin{array}{r}-0.60^{*} \\
(0.26)\end{array}$ & $\begin{array}{r}-0.46^{*} \\
(0.22)\end{array}$ \\
\hline Constant & -4.00 & -4.09 & -5.43 & 3.81 \\
\hline Log-likelihood & -44.122 & -44.148 & -41.181 & -38.470 \\
\hline
\end{tabular}

Note: Robust standard errors in parentheses (clustered on interviewer), $\mathrm{N}=72$; column 1 includes control variables for qualifications, health, marital status, age, and sex, whereas the other columns include control variables for qualifications, health, and marital status. Coefficients of control variables are in Table 3 in the online supplement.

${ }^{*} \mathrm{p}<0.05$

\section{Relative Income}

We estimate the impacts of two notions of "relative income" on trustworthiness, which differ in their reference points. For one of them, the reference point is income in the very recent past. To investigate this, we use the answers to a question we have in the questionnaire that subjects completed after the game, which records whether they thought that, in terms of their financial situation, they were better off, worse off, or about the same as they were the previous year. Figure 3 shows that those who perceived themselves to be better off (23.8 percent, $N=19)$ are much more likely to be trustworthy, but those who feel worse off ( 28.8 percent, $\mathrm{N}=23$ ) behave the same as those who describe their situation as unchanged (47.4 percent, $\mathrm{N}=38$ ). As shown in the first column of Table 2 below, when these categories are included in a logit model with the same control variables as in Table 1, the same pattern is repeated.

But the fourth column of Table 1 suggests that the longer-term past may be a better reference point than the recent past. Thus, we now take past average income (in the years 1997-2001) as reference. This measure is closely akin to the notion of relative income in the theory of Richard Easterlin $(1973,1974)$. He postulated that a person's expected standard or living, or "material aspirations" for short, is based on his past experience. A person compares his current income to his aspirations, and when the former is higher relative to the latter, he feels better off, and, in his main applications, is more disposed to marry and have children. ${ }^{10}$ Past average income may thus reflect "material aspirations" à la Easterlin and, as such, it may be one component of relative income.

Figure 4 shows the distribution of trustworthiness broken down by relative income below and above average. Those whose relative income was above the average (54 percent of the sample) had a significantly larger percentage of Es 
Table 2: Logit regression of impacts of relative income on trustworthiness.

\begin{tabular}{|c|c|c|c|c|c|}
\hline Return $£ 22$ & 1 & 2 & 3 & 4 & 5 \\
\hline $\begin{array}{l}\text { Long-term relative household } \\
\text { income }(\log )(\text { mean }=-0.14)\end{array}$ & & $\begin{array}{r}1.62^{*} \\
(0.43)\end{array}$ & $\begin{array}{r}1.75^{*} \\
(0.35)\end{array}$ & $\begin{array}{r}1.99^{*} \\
(0.45)\end{array}$ & $\begin{array}{r}3.62^{*} \\
(1.05)\end{array}$ \\
\hline $\begin{array}{l}\text { Relative income X (Income increase, } \\
\text { 1998-2001) }\end{array}$ & & & & & $\begin{array}{r}-2.80^{*} \\
(1.23)\end{array}$ \\
\hline Income increase, 1998-2001 & & & & & $\begin{array}{r}-0.80 \\
(0.83)\end{array}$ \\
\hline Better off than last year & Ref. & & & Ref. & \\
\hline Worse off than last year & $\begin{array}{r}-1.06^{*} \\
(0.51)\end{array}$ & & & $\begin{array}{c}-0.11 \\
(0.80)\end{array}$ & \\
\hline About the same as last year & $\begin{array}{r}-1.51^{*} \\
(0.67)\end{array}$ & & & $\begin{array}{r}-1.39 \\
(0.91)\end{array}$ & \\
\hline $\begin{array}{l}\text { Mean household size, } 1997-2001 \\
(\text { mean }=2.47)\end{array}$ & & $\begin{array}{r}-0.51^{*} \\
(0.25)\end{array}$ & $\begin{array}{r}-0.59^{*} \\
(0.24)\end{array}$ & $\begin{array}{r}-0.67^{*} \\
(0.29)\end{array}$ & $\begin{array}{r}-0.71^{*} \\
(0.25)\end{array}$ \\
\hline$£ 12$ treatment & & & $\begin{array}{c}-0.91 \\
(0.61)\end{array}$ & $\begin{array}{c}-0.73 \\
(0.57)\end{array}$ & $\begin{array}{c}-0.89 \\
(0.68)\end{array}$ \\
\hline Constant & 1.85 & 1.68 & 2.32 & 3.34 & 2.02 \\
\hline Log-likelihood & $-48.138^{\mathrm{d}}$ & -38.551 & -37.315 & -34.561 & $-33.780^{\mathrm{e}}$ \\
\hline
\end{tabular}

Note: Robust standard errors in parentheses (clustered on interviewer), $\mathrm{N}=72$; all models include control variables for qualifications, health, and marital status. Coefficients of control variables are in Table 3 in the online supplement.

${ }^{*} \mathrm{p}<0.05$.

d 80 observations; ${ }^{\text {e }} 71$ observations.

returning $£ 22$. Thus, we have some evidence that relative income directly affects trustworthiness.

Given the small size of our sample, it is more efficient to use the continuous measures of current and past average income rather than this discrete measure. We define the log of "long-term relative income" as the difference between log current and past average log household income; that is, we assume that the reference point (aspirations) is proportional to past income.

More specifically, our econometric specification is the following:

$$
T W_{t}=\alpha+\beta \ln \left(y_{t}\right)+\gamma \sum w_{t-k} \ln \left(y_{t-k}\right)+e
$$

where $\mathrm{TW}_{t}$ is a latent variable for trustworthiness in the experiment period $t, \mathrm{y}_{t}$ is household income in year $\mathrm{t}$, e has a logistic distribution, the sum is over $\mathrm{k}$ from 5 to 10 , and $\mathrm{w}_{t-k}$ are weights that sum to unity. We assume $\mathrm{w}_{t-k}=1 / 5$ for $\mathrm{k}=5, . ., 10$. Ignoring the control variables, this is the model estimated in the fourth column of Table 1. Our long-term relative income hypothesis is that $\beta=-\gamma$. In terms of Easterlin's ideas, each past year's contribution to "aspirations" is proportional to income in that year and the constant of proportionality is absorbed in the constant term, $\alpha .{ }^{11}$ We have seen from Table 1 that imposing the coefficients of current 


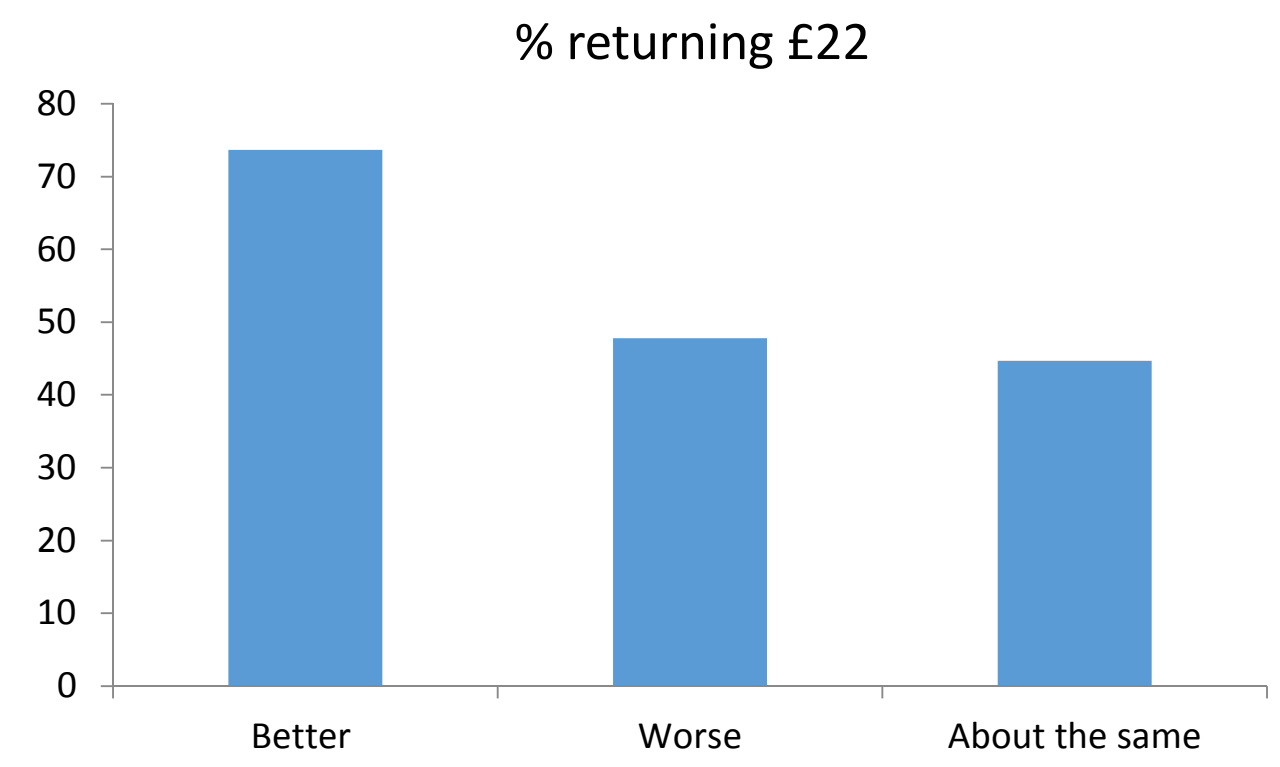

Figure 3: Perceived change in financial situation between 2006 and 2007 and trustworthiness.

and past average log income to be equal in size but opposite in sign is statistically acceptable.

The second column of Table 2 indicates that long-term relative income has a strong positive effect on TW. The third column adds the $£ 12$ treatment variable. There is a suggestion that the $£ 12$ treatment reduces trustworthiness, but its impact is imprecisely estimated. Despite our small sample, the impact of relative income is precisely estimated - the ratio of its coefficient to its standard error is five.

Adding the perceived short-term financial change categories to the model (fourth column) has little effect on the results, and we cannot reject the hypothesis that these variables can be excluded from the model $(p$-value $=0.25)$. Prospect theory (Kahneman and Tversky 1979) predicts that losses are weighted more heavily in decisions than gains, suggesting asymmetric effects of relative income. We tested whether increases and declines in current income relative to past income had the same effects but found virtually no difference $(p$-value $=0.91) .{ }^{12}$ All of the specifications show a strong and precisely estimated effect of long-term relative income and a negative effect of household size.

The interpretation of the past income component of long-term relative income is that it reflects current income expectations or aspirations, which also might be affected by the rate of change in income during 1998-2001. Two people with the same average log household income during 1997-2001 could have two dramatically different income profiles. We might expect that the person who had the rising 


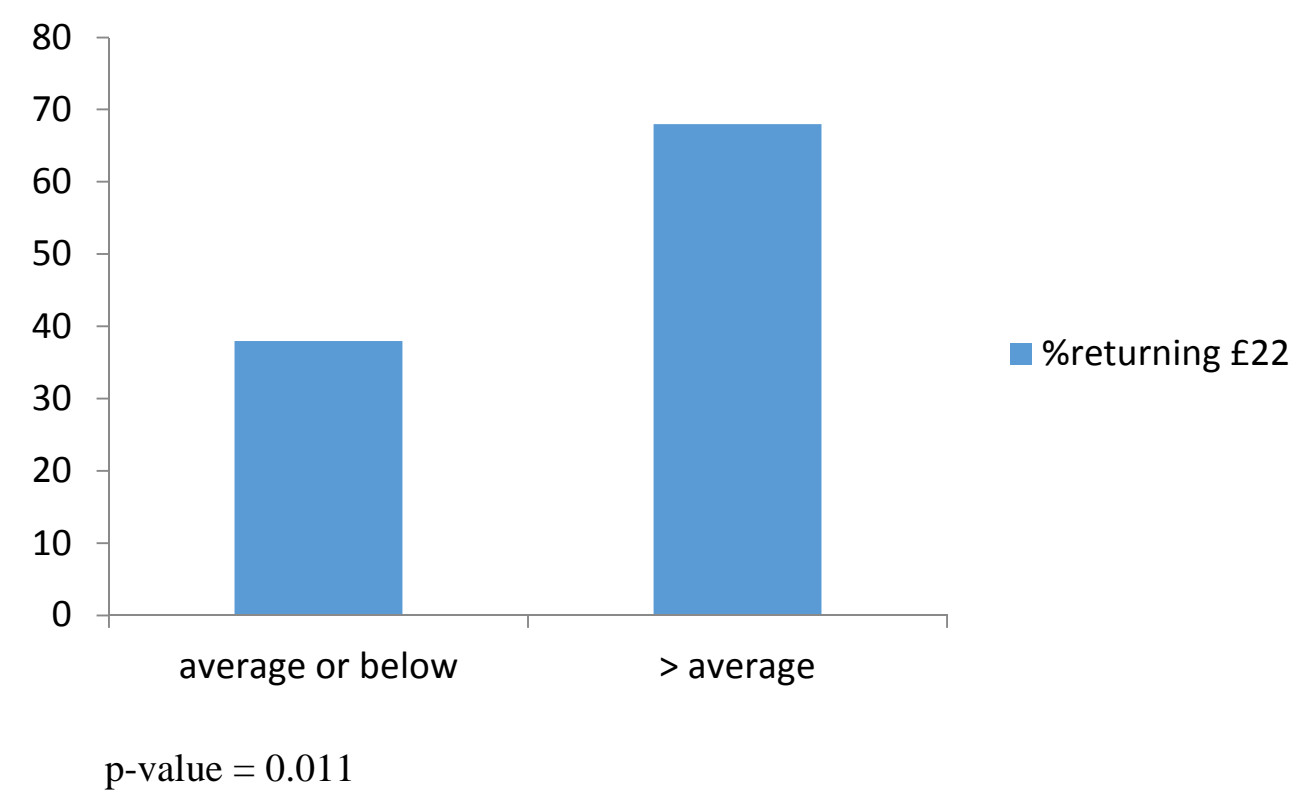

Figure 4: Long-term relative income in 2007 and trustworthiness.

income profile had higher material aspirations in 2007 than the person with the declining profile. If this is the case, then the effect of relative income on trustworthiness may be smaller for those persons whose income was increasing than for those whose income was falling. One-third of our sample experienced an income decrease during 1998-2001. In the fifth column of Table 2, we introduce an interaction variable between an indicator for an increase in income and relative income and the indicator itself. The interaction variable is statistically significant, and the impact of relative income on the log odds of returning the $£ 22$ is much higher for those whose income was constant or declining than those whose income was increasing. This lends further credence to our relative income interpretation.

\section{Conclusions}

We have developed a behavioral measure of TW in a survey context. Our basic robust finding is that, given past income, higher current income increases TW and, given current income, higher past income reduces TW. We have found that the more distant past is more relevant as a reference point for relative income than the recent past and that higher long-term relative income increases trustworthiness, 
markedly more so if income was declining in the past. The average marginal effects of a 10 percent higher relative income on the probability of being trustworthy are 4.7 percentage points $(\mathrm{SE}=0.4)$ for those whose income was decreasing, 1.5 percentage points $(\mathrm{SE}=0.9)$ for those whose income was increasing in the past, and 2.5 percentage points $(\mathrm{SE}=0.6$ ) when ignoring the distinction between the two groups. In light of a standard deviation in log relative income in the sample of 0.73 , these effects appear relatively large. The mechanism would be that material aspirations are set by the level of past income, and if they are (not) satisfied by current income subjects are more (less) likely to be TW.

Because of the positive association between current income and TW, the estimate of the proportion being trustworthy in our study sample is biased downward. Thus, the British population is relatively trustworthy in small financial transactions with strangers with more than one half resisting the temptation to obtain an additional $£ 22$.

Household size has a negative effect on TW, and its size is about the same whether absolute or relative income is the income concept (cf. Tables 1 and 2), while we also find that the divorced, separated, or widowed are more likely to be trustworthy. One interpretation of both effects is that previously married people and those living in small households have a stronger motive and greater opportunities to participate in social relationships with people outside their household and family network, making them more accustomed to both trusting strangers and being trustworthy in interactions with strangers than others with less "outward exposure." Ermisch and Gambetta (2010) found from the same game used here that divorced and separated people were indeed more likely to trust strangers, whereas people with strong family ties outside the household were less trusting. ${ }^{13}$ Put differently, members of larger households may view "outsiders" in a more opportunistic way because they interact with them less often than those living in small households or simply are socially more self-sufficient and care less about being harsh with others. On the other hand, the increase in the income coefficient accompanying the introduction of household size in the model strongly suggests an alternative interpretation, namely that the household size impact represents a control for how thinly resources must be spread in the household.

While the relative income effect is identified in our analysis by variation among people, it has potential dynamic macro-implications: TW should increase (decline) during an economic boom (recession) because current income rises (falls) relative to past income; in other words, trustworthiness is pro-cyclical. Insofar as trustworthiness positively affects economic growth, then periods of recession would be deeper and longer as a result of trustworthiness being pro-cyclical. In terms of secular income growth, as long as it is not associated with a change in the distribution of the underlying traits that affect both income and TW, it should have no long-term effects on TW. 


\section{Notes}

1 To name but a few important contributions: Gambetta 1988; Berg et al. 1995; Cook 2001; Glaeser et al. 2000; Fehr et al. 2002; McCabe et al. 2003; Bohnet and Huck 2005; Bellemare and Kröger 2007; and Schechter 2007.

2 Typical "trust questions" include the following (from the World Values Survey, General Social Survey (U.S.) and British Household Panel Study): "Generally speaking, would you say that most people can be trusted, or that you can't be too careful in dealing with people?" In a recent paper, Ermisch et al. (2009) question the usefulness of this question for measuring trust by showing it is uncorrelated with behavior in the "trust game" described below in this paper.

3 The data are available from the U.K. Data Service: People's Trust: a Survey-Based Experiment, 2007 (Persistent Identifier 10.5255/UKDA-SN-6110-1). We know of only two other instances, neither of which was in the United Kingdom, in which trust-game experiments have been carried out with a representative sample of the population and combined with survey questions - one was carried out in Germany (Fehr et al. 2002) and gave us the original inspiration, the other in the Netherlands (Bellemare and Kroeger 2007). Other trust studies have also used population samples (e.g., Barr 2003 and Schechter 2007), but ones that are less representative of the population than these two studies.

4 Triggering reciprocity and trust-responsiveness relies on the ability or motivation to read the intentions. Laboratory experiments by McCabe, Rigdon, and Smith (2003) using binary trust games similar to that used here, in which the truster's expectation is known to the trustee, suggest that the trustee's attribution of intentions to the truster is important in the trustee's decision to fulfil trust or not. The evidence in McCabe et al. (2003) is not consistent with dominance of "outcome-based preferences," such as preferences exhibiting "inequity aversion" (Fehr and Schmidt 1999), which are assumed to capture ideas of "fairness."

5 We are grateful to Abigail Barr for drawing our attention to this possibility.

6 This is related to the concept of "income comparisons," in which this a comparison to one's past self rather than to others.

7 For comparison, the corresponding correlation in the full 2007 BHPS is 0.53.

8 The reasoning is that lower-class (poorer) people experience less personal control and are (or feel) more dependent on others' help and good will to achieve desired outcomes compared with upper-class (richer) people, who are characterized by economic independence, more personal control, and more freedom of personal choice. As a consequence, lower-class people are motivated to behave in ways that promote social engagement with others, making them more accustomed to behave pro-socially in social interactions like the one in our experiment.

9 Because of non-response to the income question, the sample size shrinks to 72.

10 The relative income concept is also used to explain other behaviors, such as labor supply, savings, and reported levels of happiness; in particular, the notion is invoked to account for the lack of an upward trend in people's reports of "happiness" in surveys despite considerable growth in incomes-the so-called "Easterlin paradox" (see Clark et al. [2008] for a review).

11 Alternatively, we could assume that aspirations are proportional to average past income $\left(\sum \mathrm{y}_{t-k} / 5\right)$, and again, the proportionality factor is absorbed in the constant term. The estimates of $\beta$ and $\gamma$ are very similar in this alternative specification because the correlation coefficient between average log past income and log average past income is 0.94 . 
12 Another possibility is that those who had higher incomes in the past than currently may be disproportionately those who retired during the intervening period, and the movement into retirement may affect TW. When we include an indicator for retiring between 2001 and 2007 in the model of column 3 of Table 2 (8 percent of the sample), the coefficient of log relative income is virtually identical $(1.79, \mathrm{SE}=0.38))$ to that in column 3 , and the impact of retirement (std. error) is $0.99(0.70)$.

13 There is no evidence that strong family ties outside the household affect TW.

\section{References}

Bacharach, Michael, and Diego Gambetta. 2001. "Trust in Signs." Pp.148 -184 in Trust in Society, edited by Karen Cook. New York: Russell Sage Foundation.

Bellemare, Charles, and Sabina Kröger. 2007. "On Representative Social Capital." European Economic Review 51(1):183 -202. http://dx.doi.org/10.1016/j.euroecorev. 2006. 03.006

Barr, Abigail. 2003. "Trust and Expected Trustworthiness: Experimental Evidence from Zimbabwean villages." Economic Journal 113(489): 614-630. http://dx.doi.org/10. 1111/1468-0297.t01-1-00150

Barr, Abigail, and Pieter Serneels. 2006. "Reciprocity in the Workplace." Experimental Economics 12(1): 99 -112. http: //dx.doi.org/10.1007/s10683-008-9202-8

Becchetti, Leonardo, and Pierluigi Conzo. 2009. "Creditworthiness as a Signal of Trustworthiness." AICCON (Associazione Italiana per la Cultura della Cooperazione e del Non Profit) Research Institute Working Paper No. 67-2009.

Belot, Michelé, and John Ermisch 2009. "Friendship Ties and Geographical Mobility: evidence from the Great Britain." Journal of the Royal Statistical Society 172(2):427 -442. http: //dx.doi.org/10.1111/j.1467-985X.2008.00566.x

Berg, Joyce, John Dickhaut, and Kevin McCabe. 1995. "Trust, Reciprocity, and Social History." Games and Economic Behavior 10(1):122-142. http://dx.doi.org/10.1006/game.1995. 1027

Bohnet, Iris, and Steffen Huck. 2004. "Repetition and Reputation: Implications for Trust and Trustworthiness when Institutions Change." American Economic Review 94(2):362 -366. http://dx.doi.org/10.1257/0002828041301506

Bohnet, Iris, Heike Harmgart, Steffen Huck, and Jean-Robert Tyran. 2005. "Learning Trust." Journal of the European Economic Association 3(2-3), 322 -329. http: //dx . doi .org/10. 1162/jeea.2005.3.2-3.322

Bonein, Aurélie, and Daniel Serra. 2009. "Gender pairing bias in trustworthiness," Journal of Behavioral and Experimental Economics (formerly The Journal of Socio-Economics), Elsevier, 38(5): $779-789$.

Clark, Andrew, Paul Frijters, and Michael A Shields. 2008. "Relative Income, Happiness, and Utility: An Explanation for the Easterlin Paradox and other Puzzles." Journal of Economic Literature 46(1):95 -144. http: //dx.doi.org/10.1257/jel.46.1.95

Cook, Karen. (Ed.) 2001. Trust in Society. New York: Russell Sage Foundation

Easterlin, Richard A. 1973. "Relative Economic Status and the American Fertility Swing." Family Economic Behavior, edited by Eleanor. B.Sheldon. Philadelphia: Lippincott.

Easterlin, Richard A. 1974. "Does Economic Growth Improve the Human Lot? Some Empirical Evidence." Pp. 89 -125. Nations and Households in Economic Growth. Essays in 
Honor of Moses Abramovitz. Edited by Paul A. David and Melvin W Reder. Cambridge, MA:Academic Press. http://dx.doi .org/10.1016/b978-0-12-205050-3.50008-7

Ermisch, John, and Diego Gambetta. 2010. "Do Strong Family Ties Inhibit Trust?" Journal of Economic Behavior \& Organization. 75(3): 365-376. http://dx . doi .org/10.1016/j . jebo. 2010.05 .007

Ermisch, John, and Diego Gambetta. 2006. "People's Trust: the Design of a Survey-based experiment." Working Paper of Institute for Social and Economic Research, paper 2006-34 (PDF). University of Essex.

Ermisch, John, Diego Gambetta, Heagher Laurie, Thomas Siedler, and S.C. Noah Uhrig. 2009. "Measuring People's Trust." Journal of the Royal Statistical Society Series A. 172(4):749 -769. http://dx.doi.org/10.1111/j.1467-985X.2009.00591.x

Fehr, Ernst, and Klaus M Schmidt. 1999. "A Theory of Fairness, Competition, and Cooperation." The Quarterly Journal of Economics, 114(3):817-868. http://dx.doi .org/10 . 1162/003355399556151

Fehr, Ernst, Urs Fischerbach, Bernhard von Rosenbladt, Jürgen Schupp, and Gert G. Wagner. 2002. "A Nation-Wide Laboratory." Schmollers Jahrbuch 122:519 -542.

Gambetta, Diego 1988. "Can we trust trust?" 213-237. In Trust: Making and Breaking Cooperative Relations, edited by Diego Gambetta. Oxford: Basil Blackwell.

Gambetta, Diego, and Heather Hamill. 2005. Streetwise. How Taxi Drivers Establish their Customers' Trustworthiness. New York: Russell Sage Foundation.

Glaeser, Edward L., David I., Laibson, Jose A. Scheinkman, and Christine L. Soutter. 2000. "Measuring Trust." Quarterly Journal of Economics 115(3):811 -846. http: //dx . doi .org/ $10.1162 / 003355300554926$

Jäckle, Annette, Emanuela Sala, Stephen P. Jenkins, and Peter Lynn. 2004. "Validation of Survey Data on Income and Employment: the ISMIE Experience." Working Papers of the Institute for Social and Economic Research, paper 2004-14. University of Essex.

Kahneman, Daniel, and Amos Tversky. 1979. "Prospect Theory: An Analysis of Decisions under Risk." Econometrica 47(2):263 -291. http: //dx. doi .org/10.2307/1914185

Karlan, Dean S. 2005. "Using Experimental Economics to Measure Social Capital and Predict Financial Decisions." American Economic Review 95(5):1688-1699 http: //dx . doi .org/ $10.1257 / 000282805775014407$

Kropp, Jaclyn. D., Calum G. Turvey , David R Just, Rong Kong, and Pei Guo. 2009. "Are the Poor Really More Trustworthy? A Micro-lending Experiment." Agricultural Finance Review 69(1):67 - 87. http://dx.doi.org/10.1108/00021460910960471

McCabe, Kevin A., Mary L. Rigdon, and Vernon L. Smith. 2003. "Positive Reciprocity and Intentions in Trust Games." Journal of Economic Behavior and Organization 52(2):267 -275. http://dx.doi.org/10.1016/S0167-2681(03)00003-9

Morrison, Peter A. 1971. "Chronic Movers and the Future Redistribution of Population: A Longitudinal Analysis." Demography 8(2):171 -184. http://dx.doi.org/10.2307/ 2060607

Piff, Paul K., Michael W.Kraus, Stéphane Cote, Bonnie Hayden Cheng, and Dacher Keltner. 2010. "Having Less, Giving More: The influence of Social Class on Prosocial Behavior." Journal of Personality and Social Psychology 99(5):771 -784. http://dx.doi .org/10 . $1037 / \mathrm{a} 0020092$

Piff, Paul K, Daniel M. Stancato, Stéphane Cote, Rudolfo Mendoza-Denton, and Dacher Keltner. 2012. "Higher Social Class Predicts Increased Unethical Behaviour." Proceedings 
of the National Academy of Sciences 109(11):4086-4091 http://dx . doi .org/10.1073/ pnas. 1118373109

Schechter, Laura. 2007. "Traditional Trust Measurement and the Risk Confound: An Experiment in Rural Paraguay." Journal of Economic Behavior and Organization 62(2): 272 -292. http://dx.doi.org/10.1016/j.jebo.2005.03.006

Acknowledgements: We are grateful to the U.K. Economic and Social Research Council (People's Trust: A Survey-based Experiment, RES-000-22-2241) for financial support for the research.

John Ermisch: Department of Sociology and Nuffield College, University of Oxford. E-mail: john.ermisch@sociology.ox.ac.uk.

Diego Gambetta : European University Institute, Florence. E-mail: diego.gambetta@eui.eu. 